\title{
Grey Correlation Analysis of Factors Affecting Wood Drying in PCM Thermal Storage Solar Drying System
}

\author{
Yu Jie ${ }^{1}$, Zheng Maosheng ${ }^{2}$ \\ ${ }^{1}$ School of Life Science \& Technology, Northwest University, Xi'an, China \\ ${ }^{2}$ School of Chemical Engineering, Northwest University, Xi'an, China \\ Email address: \\ mszhengok@aliyun.com (Zheng Maosheng)
}

\section{To cite this article:}

Yu Jie, Zheng Maosheng. Grey Correlation Analysis of Factors Affecting Wood Drying in PCM Thermal Storage Solar Drying System. Mathematical Modelling and Applications. Vol. 2, No. 3, 2017, pp. 28-32. doi: 10.11648/j.mma.20170203.11

Received: May 10, 2017; Accepted: June 6, 2017; Published: July 14, 2017

\begin{abstract}
The gray correlation analysis is employed to analyze the effect of the row number of thermal storage tubes, the air circulation rate and the air temperature on efficiency of wood drying in solar drying system with phase change material (PCM) thermal storage, the relative order of influencing factors on wood drying process is determined. It indicated that air temperature is the $1^{\text {st }}$ key influencing factor in the solar drying system, followed by the air circulation rate, and then the row number of thermal storage tubes. This result is of practical significance for the optimization of the drying process.
\end{abstract}

Keywords: Grey Correlation, Solar Wood Drying, Air Temperature, Circulation Rate, Thermal Storage Tube Row

\section{Introduction}

Use of solar energy for drying agricultural products is one of the important production activities, which were carried out very early in human society [1]. In nowadays, the energy shortage and environmental pollution restrict economic development and threat to living environment, so much more attention has been paid to the use of solar energy. The modern solar drying technology refers to the use of hot air to dry materials, while the warm air is obtained by a collector of solar radiation and transfer it into heat energy. Solar drying can not only greatly reduce the drying time and improve product quality, but also can play a role in energy saving.

China has abundant solar energy resources, it has about two-thirds of land with annual irradiation time over 2200 hours [1], the annual total radiation is over $5000 \mathrm{MJ} / \mathrm{m}^{2}$, the total solar radiation in the country is $3340 \mathrm{MJ} / \mathrm{m}^{2} \sim 8400 \mathrm{MJ} /$ $\mathrm{m}^{2}$ per year. Especially, it is very suitable to carry out application of solar energy in the region of the latitude range $35^{\circ} \sim 45^{\circ}$. The areas with plenty of solar energy resource includes Tibetan plateau, northern Gansu, Ningxia, southern Xinjiang, northwestern Hebei, northern Shanxi, Inner Mongolia, central Gansu, eastern Qinghai, southeastern Tibet, etc.

Wood drying is most important process in wood production process, it costs about $40 \%$ to $70 \%$ of energy consumption of the whole wood production in China [2]. The use of solar drying in wood production has been launched in many countries [2-5]. However, the total drying capacity of solar drying in China is approximately $0.2 \%$ of the drying production [5], so it needs to be improved.

The factors that restrict the use of solar drying include mainly the low energy density of solar resource, the seasonal performance, and poor storage of energy.

Feng et al. studied wood drying by solar technology with phase change thermal storage [6], in which a small test rig with phase change thermal storage system is set up to simulate the drying process of wood drying apparatus. The experimental result gives some rules of the effect of the number of thermal storage pipe rows, the rate and the temperature of circulation air on the drying efficiency, it is useful to optimize the drying system.

Grey theory was proposed by Deng in 1982 [7-14], and it has been applied in many ways, and gratifying results are achieved. The Grey system theory is based on "knowing partial information, unknowing partial information", "small sample", "poor information", and "uncertainty system", it realizes the operation behavior, the correct description and the evolution of a system mainly by extracting valuable information and generation and development of knowing partial information.

Furthermore, the order of affecting factors needs to be recognized by gray correlation analysis. 
In this paper, the gray correlation degree analysis is employed to study the influence of affecting factors on wood drying in solar drying system with phase change thermal storage conducted by [6].

\section{Materials and Methods}

\subsection{Outline of Feng's Drying Test}

In Feng's test [6], the test material is poplar produced from the Beijing suburb with the initial moisture content in the range of $78 \%$ to $83 \%$. The size of test material specifications: $350 \times 40 \times 40 \mathrm{~mm}(\mathrm{~L} \times \mathrm{W} \times \mathrm{H})$, with volume of $0.01 \mathrm{~m}^{3}$.

A small test bed is employed which contains a thermal storage system [6], a heating system, an air circulation system and a data acquisition system. The thermal storage system consists of a metal box with a number of $10 \mathrm{~mm}$ holes in radius for inserting thermal storage aluminum-pipe of paraffin, the air circulation path is formed between the thermal storage aluminum-pipe of paraffin. The phase transition temperature of the paraffin is about $54^{\circ} \mathrm{C}$. The electric heater is taken as a supplement for heat energy, the rate and the temperature of the circulation air can be adjusted. The rate of the circulation air is $1.0,1.5,2.0 \mathrm{~m} / \mathrm{s}$, respectively.

The test is repeated for 9 times for each test condition. Figure 1 shows the arrangement of paraffin tubes in the thermal storage system [6].

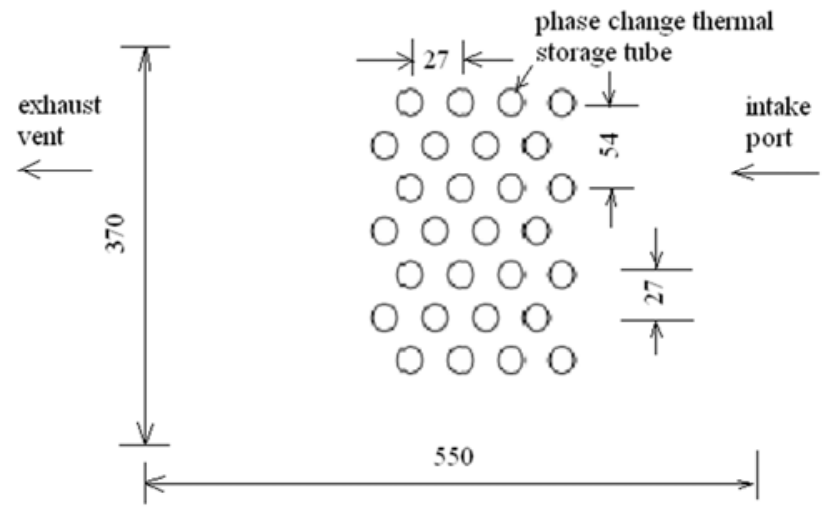

Figure 1. Arrangement of paraffin tubes in the thermal storage system.

\subsection{Fundamental of Grey Correlation Degree}

Since the proposal of Grey theory in his "Control problems of grey systems" by Prof. Deng in 1982 [7], the Grey Correlation Degree theory has been developed gradually [8-14].

It deal with the system with partial information clear and partial unclear, i.e., relatively poor information systems. While, in traditional system theory, more information was need adequately. For some relatively poor information systems, the use of black-box approach also made a more successful experience. However, the research is very inadequate for the system with some internal information ascertain and partial information unknown. This blank area becomes the birthplace of Grey System Theory.

Gray Correlation analysis is a multivariate statistical analysis method, which is based on the sample data of various factors. If the trends of two factors (orientation, size and speed, etc.) of the sample data are basically the same, the correlation degree between these two factors is greater; on the contrary, a smaller correlation degree. Therefore, the gray correlation method is based on the degree of similarity or dissimilarity between the trends of factors.

The advantage of this approach is thinking clear, reducing loss due to the asymmetric information to a large extent, and less workload.

The basic procedure for analyzing the gray correlation is as follows:

(1) Determining the representing "number of columns" of the system behaviour and the reference "number of columns" of the system;

(2) Non-dimensional treatment for the reference "number of columns" and comparative the "number of columns";

(3) Calculating the gray correlation coefficient between the reference "number of columns" and compare "number of columns";

(4) Calculating related degree;

(5) Arranged order correlation degree.

\section{Analysis of Grey Correlation Degree}

\subsection{Feng's Experimental Results}

The basic idea of gray correlation analysis is based on the geometric similarity of sequence curves to determine the closeness [13, 14]. The closer the curves, the greater correlation degree of the sequences. The mapping is the $1^{\text {st }}$ step to perform the analysis.

According to the test results of Feng et al. [6], the effect of the influence of affecting factors on drying efficiency is sort out systematically. The effect of the number of tube rows on the wood drying efficiency is represented in Table 1.

Table 1. Effect of number of thermal storage tube rows on drying rate [6].

\begin{tabular}{lllll}
\hline Number of tube rows & $\mathbf{5}$ & $\mathbf{7}$ & $\mathbf{1 1}$ & $\mathbf{1 3}$ \\
\hline Drying rate $\left(\% \cdot \mathrm{h}^{-1}\right)$ & 1.04 & 1.11 & 1.04 & 0.99 \\
\hline
\end{tabular}

Table 2 shows the effect of the circulation rate of air on the wood drying efficiency under condition of the thermal storage number of tube rows 7 and the air temperature is $60^{\circ} \mathrm{C}$ [6].

Table 2. Effect of air circulation rate on the wood drying efficiency (thermal storage tube rows number of 7 and the air temperature of $60^{\circ} \mathrm{C}$ ).

\begin{tabular}{llll}
\hline Circulation rate of air $(\mathbf{m} / \mathbf{s})$ & $\mathbf{1 . 0}$ & $\mathbf{1 . 5}$ & $\mathbf{2 . 0}$ \\
\hline Drying efficiency $\left(\% \cdot \mathrm{h}^{-1}\right)$ & 0.68 & 0.98 & 0.75 \\
\hline
\end{tabular}

Table 3 shows the influence of temperature of circulation air on drying efficiency under condition of 11 thermal storage tube rows and the air rate of $1.5 \mathrm{~m} / \mathrm{s}$.

Table 3. The influence of temperature of circulation air on drying efficiency under condition of 11 thermal storage tube rows and air rate of $1.5 \mathrm{~m} / \mathrm{s}$.

\begin{tabular}{llll}
\hline Temperature of circulation air $\left({ }^{\circ} \mathbf{C}\right)$ & $\mathbf{5 5}$ & $\mathbf{6 0}$ & $\mathbf{6 5}$ \\
\hline Drying efficiency $\left(\% \cdot \mathrm{h}^{-1}\right)$ & 0.83 & 0.95 & 1.06 \\
\hline
\end{tabular}




\subsection{Calculation of Gray Correlation}

The drying rate is the target parameter of the drying process $[13,14], y_{i}$. While the variables of the system includes, the number of thermal storage tube rows, the temperature and the rate of circulation air, $\mathrm{x}_{\mathrm{i}}$.

Therefore, above data processing needs to be rewritten in accordance with the gray theory as

$$
\begin{gathered}
\mathrm{y} 1=\{1.04,1.11,1.04\}, \mathrm{x} 1=\{5,7,11\} \\
\mathrm{y} 2=\{0.68,0.98,0.75\}, \mathrm{x} 2=\{1.0,1.5,2.0\} \\
\mathrm{y} 3=\{0.83,0.95,1.06\}, \mathrm{x} 3=\{55,60,65\}
\end{gathered}
$$

wherein, $\mathrm{y}_{1}, \mathrm{y}_{2}$, and $\mathrm{y}_{3}$ represent the target factors, i.e. drying rate. $\mathrm{x}_{1}, \mathrm{x}_{2}$, and $\mathrm{x}_{3}$ represent the number of thermal storage tube rows, rate of the circulating air, the temperature of the circulating air, correspondingly.

\subsubsection{Calculation of Grey Generalized Absolute Correlation}

According to the gray theory $[13,14]$, the gray correlation degree can be obtained for the three sets of data of the previous section. Specification follows these steps:

1), Setting a starting point image for each sequence

$$
\begin{gathered}
\mathrm{y}_{1}^{0}=\{0,0.07,0\}, \quad \mathrm{x}_{1}^{0}=\{0,2,6\} \\
\mathrm{y}_{2}^{0}=\{0,0.30,0.07\}, \mathrm{x}_{2}^{0}=\{0,0.5,1.0\} \\
\mathrm{y}_{3}^{0}=\{0,0.12,0.23\}, \mathrm{x}_{3}{ }_{3}=\{0,5,10\}
\end{gathered}
$$

2), Getting $\left|Y_{s 1}\right|,\left|X_{s 1}\right|,\left|X_{s 1}-Y_{s 1}\right|$

$$
\begin{gathered}
\left|Y_{s I}\right|=\left|\sum_{k=2}^{2} y_{1}{ }^{0}(k)+\frac{1}{2} y_{1}{ }^{0}(3)\right|=0.07 \\
\left|X_{s I}\right|=\left|\sum_{k=2}^{2} x_{1}{ }^{0}(k)+\frac{1}{2} x_{1}{ }^{0}(3)\right|=5.00 \\
\left|X_{s 1}-Y_{s 1}\right|=\left|\sum_{k=2}^{2}\left[x_{1}{ }^{0}(k)-y_{1}{ }^{0}(k)\right]+\frac{1}{2}\left[x_{1}{ }^{0}(3)-y_{1}{ }^{0}(3)\right]\right|=4.93
\end{gathered}
$$

3), Calculation of Gray absolute correlation degree

$$
\varepsilon_{11}=\frac{1+\left|X_{s 1}\right|+\left|Y_{s 1}\right|}{1+\left|X_{s 1}\right|+\left|Y_{s 1}\right|+\left|X_{s 1}-Y_{s 1}\right|}=\frac{6.07}{11.00}=0.5518
$$

Similarly, it could calculate other gray generalized absolute correlation,

$$
\begin{aligned}
& \varepsilon_{11}=0.5518, \varepsilon_{12}=0.6900, \varepsilon_{13}=0.5271 \\
& \varepsilon_{21}=0.5759, \varepsilon_{22}=0.7783, \varepsilon_{23}=0.5398 \\
& \varepsilon_{31}=0.5668, \varepsilon_{32}=0.7450, \varepsilon_{33}=0.5350
\end{aligned}
$$

It gives absolute correlation matrix

$$
A=\left(\varepsilon_{i j}\right)=\left[\begin{array}{lll}
\varepsilon_{11} & \varepsilon_{12} & \varepsilon_{13} \\
\varepsilon_{21} & \varepsilon_{22} & \varepsilon_{23} \\
\varepsilon_{31} & \varepsilon_{32} & \varepsilon_{33}
\end{array}\right]=\left[\begin{array}{lll}
0.5518 & 0.6900 & 0.5271 \\
0.5759 & 0.7783 & 0.5398 \\
0.5668 & 0.7450 & 0.5350
\end{array}\right]
$$

\subsubsection{Calculation of Gray Relative Relation}

Similarly, according to the gray theory $[13,14]$, it can be obtained gray relative relation. The specification follows these steps:

1), Setting initial features and starting image of the sequences $[13,14]$,

$$
\begin{gathered}
Y_{1}^{\prime}=(1.00,1.07,1.00), X_{1}^{\prime}=(1.0,1.4,2.2) \\
Y_{2}^{\prime}=(1.00,1.44,1.10), X_{2}^{\prime}=(1.0,1.5,2.0) \\
Y_{3}^{\prime}=(1.00,1.14,1.28), X_{3}^{\prime}=(1.00,1.09,1.18)
\end{gathered}
$$

2), The starting point image of zero $Y_{i}^{\prime}$ and $X_{j}^{\prime}$ are $[13,14]$,

$$
\begin{gathered}
\mathrm{Y}_{1}{ }^{0}=(0,0.07,0), \mathrm{X}_{1}{ }^{0}=(0,0.4,1.2) \\
\mathrm{Y}_{2}{ }^{\prime 0}=(0,0.44,0.10), \quad \mathrm{X}_{2}{ }^{\prime 0}=(0,0.5,1.0) \\
\mathrm{Y}_{3}{ }^{00}=(0,0.14,0.28), \quad \mathrm{X}_{3}{ }^{\prime 0}=(0,0.09,0.18)
\end{gathered}
$$

3), Getting $\left|Y_{s i}{ }^{\prime}\right|,\left|X_{s i}{ }^{\prime}\right|$ and $\left|X_{s i}{ }^{\prime}-Y_{s i}{ }^{\prime}\right|$

$$
\begin{gathered}
Y_{s i}{ }^{\prime}|=| \sum_{k=2}^{2} y_{1}{ }^{\prime 0}(k)+\frac{1}{2} y_{1}{ }^{\prime 0}(3) \mid=0.07 \\
\left|X_{s i}{ }^{\prime}\right|=\left|\sum_{k=2}^{2} x_{1}{ }^{\prime 0}(k)+\frac{1}{2} x_{1}{ }^{\prime 0}(3)\right|=1.00
\end{gathered}
$$




$$
\left|X_{s i}{ }^{\prime}-Y_{s i}{ }^{\prime}\right|=\left|\sum_{k=2}^{2}\left[x_{l}{ }^{\prime 0}(k)-y_{l}{ }^{\prime 0}(k)\right]+\frac{1}{2}\left[x_{l}{ }^{\prime 0}(3)-y_{l}{ }^{\prime 0}(3)\right]\right|=0.93
$$

4) Getting grey relative relation

According to the algorithm of gray relative relation [6], it gives a gray relative relation $\gamma_{11}=\frac{1+\left|Y_{s 1}^{\prime}\right|+\left|X_{s 1}^{\prime}\right|}{1+\left|Y_{s 1}^{\prime}\right|+\left|X_{s 1}^{\prime}\right|+\left|X_{s 1}^{\prime}-Y_{s 1}^{\prime}\right|}=0.6891$.

Similarly, it can be calculated the remaining

$$
\begin{aligned}
& \gamma_{11}=0.6891, \gamma_{12}=0.6891, \gamma_{13}=0.9160 \\
& \gamma_{21}=0.8309, \gamma_{22}=0.8309, \gamma_{23}=0.8434 \\
& \gamma_{31}=0.7611, \gamma_{32}=0.7611, \gamma_{33}=0.9353,
\end{aligned}
$$

and the relative incidence matrix,

$$
B=\left(\gamma_{i j}\right)=\left[\begin{array}{lll}
\gamma_{11} & \gamma_{12} & \gamma_{13} \\
\gamma_{21} & \gamma_{22} & \gamma_{23} \\
\gamma_{31} & \varepsilon_{32} & \gamma_{33}
\end{array}\right]=\left[\begin{array}{lll}
0.6891 & 0.6891 & 0.9160 \\
0.8309 & 0.8309 & 0.8434 \\
0.7611 & 0.7611 & 0.9353
\end{array}\right]
$$

\subsubsection{Getting Comprehensive Correlation Matrix C}

According to the definition of comprehensive correlation matrix $C, C=\theta \cdot A+(1-\theta) \cdot B$, it takes $\theta=0.5$ in general $[13,14]$, then

$$
\begin{aligned}
\mathrm{C} & =\theta \cdot \mathrm{A}+(1-\theta) \cdot \mathrm{B}=\theta \cdot \varepsilon_{\mathrm{ij}}+(1-\theta) \cdot \gamma_{\mathrm{ij}}=\rho_{\mathrm{ij}} \\
& =\left[\begin{array}{lll}
\rho_{11} & \rho_{12} & \rho_{13} \\
\rho_{21} & \rho_{22} & \rho_{23} \\
\rho_{31} & \rho_{32} & \rho_{33}
\end{array}\right]=\left[\begin{array}{lll}
0.6205 & 0.6896 & 0.7216 \\
0.7034 & 0.8041 & 0.6916 \\
0.6639 & 0.7530 & 0.7351
\end{array}\right]
\end{aligned}
$$

\subsection{Results}

Look at the absolute correlation matrix $\mathrm{A}$, it can be found that there exists $\varepsilon_{\mathrm{i} 2}>\varepsilon_{\mathrm{i} 1}>\varepsilon_{\mathrm{i} 3}, \mathrm{i}=1,2,3$; therefore order of priority is $X_{2}, X_{1}$ and $X_{3}$, which means that the impact of circulation rate of air is the main affecting factor, followed by the number of thermal storage tube rows, and the air temperature.

While, as to the relative correlation sequence $\mathrm{B}$, it holds $\gamma_{\mathrm{i} 3}$ $>\gamma_{i 2}=\gamma_{i 1}, i=1,2,3$; therefore order of priority is $X_{3}, X_{2}$ and $X_{1}$.

However, as to the comprehensive correlation matrix $\mathrm{C}$, it holds, $\sum_{i=1}^{3} \rho_{i 2}>\sum_{i=1}^{3} \rho_{i 3}>\sum_{i=1}^{3} \rho_{i 1}$, therefore order of priority is $X_{2}, X_{3}$ and $X_{1}$.

The results of above importance ranking from the previous matrix A, B and C disagree with each other, which is because the calculation algorithm of each correlation degree pays to its special attention. Here the main point is the effect of various factors on the wood drying rate, the relative correlation analysis prevail.

\section{Conclusion}

In this paper, the use of multifactor gray theory is conducted, which analyze the effect of various affecting factors on the wood drying efficiency in a solar dryer with phase change thermal storage comprehensively. It was indicated that the air temperature is the $1^{\text {st }}$ key influencing factor in the in solar drying system, followed by the air circulation rate, and the number of thermal storage tube rows. This result is of practical significance for the optimization of the drying process.

\section{References}

[1] Wang H., Liu Y. (2013) Research and application of solar drying technology and equipment for agricultural products, Processing of agricultural products, 11, 22-23.

[2] Que G. (2007) Sustainable Development Strategy, Foreign Languages Press, Beijing, China.

[3] Scharters W. (1990) Passive solar greenhouse dryer and its development, New Energy, 12 (10), 51-56.

[4] Zhang B. (2000) Study on drying lumber with solar energy. 12nd International Drying Symposium, Netherlands.

[5] Zhang J., Ding Y., Chen N. (2005) Research and application of phase change storage materials, Salt Lake Research, 13 (3), 52-57.

[6] Feng X., Yi S., Zhang B. et al. (2010) Effect of various factors on wood drying rate in solar thermal storage phase transformation system, J. of Northern China Electric Power University, 37 (3), 79-83.

[7] Deng J. (1982) Control problems of grey systems, Systems \& Control Letters, 1 (5), 288-294.

[8] Xi Y., Wu X., Zheng X. (2014) Grey correlation analysis between mikimotoi population density and physicochemical factors, Fishery Sciences, 33 (7), 410-416.

[9] Qu Y., Zhang L., Duan J. (2014) Correlation analysis and spatial diversity of land use in central Henan, Anhui Agricultural Sciences, 41 (2), 253-259. 
[10] Hou X., Jiang B. (2014) Gray correlation analysis for tomato quality and processing, Agricultural Mechanization Research, $3,54-57$.

[11] Wang X., Zou N., Zhou Y et al. (2014) Effectiveness of gray correlation degree theory in fault identification of motor bar broking, Coal Mechanical, 5, 96-99.

[12] Hu W. (2015) Preparation of polycarboxylate superplasticizer based on gray correlation analysis, Municipal Technology, 33 (1), 171-173.

[13] Liu S., Xie N. et al. (2008) Grey system theory and its application, 4th Edition. Science Press, Beijing, China.

[14] Zhou X. (2007) Gray correlation study and its application, Theses of master degree, Jilin University, Changchun, China. 